\title{
Caries-free subjects have high levels of urease and arginine deiminase activity
}

\author{
Evelyn REYES ${ }^{1}$, Javier MARTIN², Gustavo MONCADA ${ }^{2}$, Miguel NEIRA ${ }^{3}$, Patricia PALMA ${ }^{4}$, Valeria GORDAN ${ }^{5}$, Juan \\ Fernando OYARZO ${ }^{6}$, Ismael YEVENES ${ }^{3}$
}

\author{
1- Faculty of Dentistry, University of Chile, Santiago, Chile. \\ 2- Department of Operative Dentistry, Faculty of Dentistry, University of Chile, Santiago, Chile. \\ 3- Institute for Research in Dental Sciences, Faculty of Dentistry, University of Chile, Santiago, Chile. \\ 4- Department of Pathology, Faculty of Dentistry, University of Chile, Santiago, Chile. \\ 5- Department of Operative Dentistry, College of Dentistry, Health Science Center, University of Florida, Gainesville, USA. \\ 6- Odontological Science Department, Faculty of Dentistry, Universidad Andres Bello, Santiago, Chile.
}

Corresponding address: Ismael Yévenes - Institute for Research in Dental Sciences, Faculty of Dentistry, University of Chile - Sergio Livingstone 943 Independencia - Santiago - Chile - Phone: 056-02-9781718 - Postal Adresses: 838-0492 - e-mail: iyevenes@odontologia.uchile.cl

Submitted: November 7, 2013 - Modification: March 19, 2014 - Accepted: March 28, 2014

\section{ABSTRACT}

\begin{abstract}
bjectives: This study investigated the relationship between urease and arginine deiminase system (ADS) activities and dental caries through a cross-sectional study. Material and Methods: Urease and ADS activities were measured in saliva and plaque samples from 10 caries-free subjects and 13 caries-active. Urease activity was obtained from the ammonia produced by incubation of plaque and saliva samples in urea. ADS activity was obtained from the ammonia generated by the arginine- $\mathrm{HCl}$ and Tris-maleate buffer. Specific activity was defined as micromoles of ammonia per minute per milligram of protein. Shapiro-Wilk statistical test was used to analyze the distribution of the data, and Mann-Whitney test was used to determine the significance of the data. Results: The specific urease activity in saliva and plaque was significantly higher in individuals with low DMFT scores. ADS activity in saliva (6.050 vs $1.350, p=0.0154)$ and plaque (8.830 vs $1.210, p=0.025)$ was also higher in individuals with low DMFT scores. Conclusions: Cariesfree subjects had a higher ammonia generation activity by urease and arginine deiminase system for both saliva and plaque samples than low caries-active subjects. High levels of alkali production in oral environment were related to caries-free subjects.
\end{abstract}

Keywords: Alkali. Arginine. Dental plaque. Saliva. Urease. Dental caries.

\section{INTRODUCTION}

Dental caries is the most prevalent oral disease, comprising almost $100 \%$ of the world population, generating an epidemiological problem in all countries ${ }^{27}$. The transition from oral health to such disease is characterized by compositional and metabolic changes of the oral biofilm ${ }^{5,23}$. Factors recognized as having more influence over composition and activity of oral biofilm, and over its pathogenic potential, are $\mathrm{pH}$, source and availability of nutritional substances such as carbohydrates ${ }^{6}$.

The focus on an oral environment with a low $\mathrm{pH}$ has been dominant when teaching or researching in dental caries. The acidification of oral biofilm permits the appearance of a microflora that generates acid and is capable to resist this condition, lowering the $\mathrm{pH}$ to a level that can lead to tooth demineralization ${ }^{4,14,20}$.

A new approach in caries research is focused on the fact that alkali generation from salivary substrates, like urea and arginine, may play an important role in biofilm $\mathrm{pH}$, homeostasis and in inhibiting dental caries ${ }^{6,15,26}$. The two primary sources of alkali generation in dental plaque and saliva are through the hydrolysis of urea by urease enzymes and the metabolism of arginine by the arginine deiminase system (ADS) 9,23,24,32. It has been described that in caries-resistant subjects a more alkaline biofilm is encountered ${ }^{20}$. In contrast, caries risk may be associated with the loss of alkali generation potential15-17,31.

Urea can be found in every salivary gland secretion in concentrations similar to those of 
serum, oscillating between 1 and $10 \mathrm{mM}^{13,18}$. Arginine in its free form is secreted in median concentrations of approximately $50 \mu \mathrm{M}$, being also abundant in salivary peptides and proteins ${ }^{31}$. In recent years, alkali production in biofilm and saliva has been studied, showing a positive relation between alkali generation, expressed as high levels of urease and arginine deiminase activity, and caries resistance, in caries-free patients compared to caries-active patients ${ }^{24}$. Gordan, et al. ${ }^{15}$ (2010) observed a positive relation between $S$. salivarius and urease activity and a negative relation between S. mutans levels and arginine deiminase.

Therefore, ammonia produced from urea and/or arginine by urealisis or the arginine deiminase system may be an important endogen inhibitory factor to acidogenic microbiota and caries development, by neutralizing acids and stabilizing oral microbiota ${ }^{6,24,26}$. For example, indirect evidence that the oral metabolism of urea may enhance caries resistance is seen in a study involving patients with chronic renal failure. These patients rarely develop caries despite a carbohydrate-rich diet. They are also able to produce 10 - to 50 -fold greater salivary urea levels than healthy subjects ${ }^{8,12,28}$. If so, the alkalinogenic potential of the oral biofilm and saliva could be established as a promising strategy in preventing or controlling dental caries. The question is: is there a relationship between oral alkali production by specific bacterial strains dental in biofilm and saliva and dental caries? For this, we propose the following hypothesis: increased production of alkaline substances by dental biofilm bacterial strains and saliva is associated with low incidence of dental caries lesions.

The aim of the present study was (1) to measure ammonia produced by urea and arginine via urease and arginine deiminase in saliva and plaque and (2) establish whether there are differences in the specific activity of urease and ADS systems from saliva and plaque, between caries-free and cariesactive subjects.

\section{MATERIAL AND METHODS}

\section{Ethical considerations}

This cross-sectional study received approval from the Human Research Ethics Committee of the School of Dentistry, University of Chile (Chile), under the protocol number ACTA W: 2012/13.

\section{Subjects}

The sample size was determined by the criterion for statistical significance. Simplified criterion is the use of an " $n$ " greater than 20 yields a normal distribution and, with a sample size of $n=20$, the shape of the distribution of the correlation coefficients of the sample is virtually identical to the distribution Normal, where only $0.5 \%$ of the sample values of $r$ will deviate from zero to within \pm 0.50 . This is justified by the sample size resulting statistically significant. The sample size of 23 subjects (10 male and 13 female) attended at the Dental Clinic of Universidad de Chile Dental School was included in the study: 10 caries-free subjects (total number of decayed, missing and filled teeth for each participant, DMFT=0), and another 13 active-caries subjects, having at least 4 teeth with active caries, formed the two study groups. Our sample was based previous studies that showed significant differences of enzymatic when DMFT was 4 active caries lesions, compared with caries-free subjects ${ }^{15,24}$.

To participate in the study, all subjects had to be 18 years old or older, have 20 or more teeth in the mouth and to be able to read and sign an informed consent form. Patients had a salivary test prior to entering the study, unstimulated salivary flow rate was collected for 5 minutes and was expressed in $\mathrm{ml}$ of saliva per minute. The following subjects were excluded from the study:

Subjects with low salivary flow (less than 0.5 $\mathrm{ml} / \mathrm{min}$ for females and $0.7 \mathrm{ml} / \mathrm{min}$ for males, the cut-off value for stimulated whole saliva flow rate $\left.{ }^{25,26}\right)$, who had used antibiotics or chlorhexidine in the previous month, with systemic diseases that precluded dental treatment, who used toothpaste containing arginine, or who had received dental bleaching treatment in the previous month.

Patients with periodontal disease were not included, since the biofilm involved in the pathogenesis of periodontal disease is characterized by a lower proportion of acidogenic bacteria; however, abound in it ureolytic bacteria producing urease and ADS metabolizing nitrogenous substrates from saliva (urea, uric acid, creatinine and amino acids), releasing ammonia that reacts with carbon dioxide forming ammonium carbonate which increases the $\mathrm{pH}$ of the biofilm ${ }^{11}$.

\section{Sample collection}

Saliva and supragingival plaque samples from all subjects were collected. For saliva samples, subjects were instructed not to eat for 12 hours prior to the sample collection, abstaining from any type of oral hygiene ${ }^{15}$. Non-stimulated saliva was collected by telling the patient to expectorate $3 \mathrm{ml}$ of saliva in a Falcon sterile plastic tube (Falcon No. 2070; Becton Dickinson Co., Franklin Lakes, NJ, USA) at $4^{\circ} \mathrm{C}$ during the sample collection.

For supragingival plaque collection, sterile periodontal curettes (GR 4/5, Gracey finishing curettes, Ransom and Randolph, Toledo, OH, USA) were used. Supragingival plaque was collected from all dental buccal surfaces of right/left and upper/ lower incisors and molars and transferred to sterile 
Eppendorf tubes with $500 \mu \mathrm{l}$ of $10 \mathrm{mM} \mathrm{K}_{2} \mathrm{HPO}_{4}$ (Mallinckrodt Baker, Inc. Newburyport, MA, USA) $\mathrm{pH} 7$ solution. Eppendorf tubes were maintained at $4^{\circ} \mathrm{C}$ during sample collection.

All samples (saliva and plaque) were frozen and stored at $-80^{\circ} \mathrm{C}$ (Sanyo Electric Co Itd, Osaka, Japan) until the day of analysis. The unfreezing of samples was done leaving them in refrigerator at $4^{\circ} \mathrm{C}$. Then, samples were dispersed by external sonication (Transsonic 460/H, Elma GmbH \& Co KG, Singen, Germany) in 2 cycles of 30 seconds each, refrigerated with ice during intervals.

\section{Biochemical measurement of ADS and urease}

Analysis of the samples was performed at the Chemistry Laboratory of the School of Dentistry, University of Chile. After thawing, an aliquot of plaque and saliva, a buffer Tris-maleate (SigmaAldrich Chemie $\mathrm{GmbH}$, Steinheim, Germany) and an exact amount of urea (Sigma-Aldrich Chemie $\mathrm{GmbH}$, Steinheim, Germany) $25 \mu$ moles was added as substrate for enzymatic action.

Ammonia (produced by urealisis or the arginine deiminase system) of saliva and plaque samples were determined spectrophotometrically (Thermo Spectronic Unicam UV-530 UV-Visible, Rochester, NY, USA). For that, an ammonia calibration curve was created by Nessler's curve, where different known ammonia concentrations were mixed with Nessler's Reagent (Sigma-Aldrich Chemie GmbH, Steinheim, Germany) generating a yellow coloration that was measured by the spectrophotometer, creating a curve of ammonia concentration $\mathrm{v} / \mathrm{s}$ absorbance. The equation of the curve was obtained and used to determine ammonia concentration (mM) of processed samples. Absorbance of saliva and plaque samples was measured using Nessler's reactive at a wavelength of $395 \mathrm{~nm}$.

As saliva and plaque samples of every patient are different and difficult to standardize, it is necessary to express ammonia and its concentration produced by proteins presented in a known volume. So, ammonia produced by urease or arginine deiminase was divided by protein concentration. For this, proteins presented in the samples were determined spectrophotometrically. A protein calibration curve was created, by Bradford's curve, where different known protein (albumin from bovine serum, SigmaAldrich, USA) (Sigma-Aldrich, St. Louis, MO, USA) concentrations were mixed with Bradford Reagent (Sigma-Aldrich, USA) (Sigma-Aldrich, St. Louis, MO, USA) generating a blue coloration that was measured by the spectrophotometer, creating a curve of protein concentration $\mathrm{v} / \mathrm{s}$ absorbance. The equation of the curve was obtained and used to determine protein concentration of processed samples. Absorbance was measured at a wavelength of $595 \mathrm{~nm}$.

Within the measurements explained below, in a first step, after centrifugation, the pellet of the samples containing the enzymes present in the saliva and plaque is used. The urea and arginine substrates are added to this pellet in order to make them react for a determined time.

After the reaction, there is a second centrifugation using the supernatant of the reaction where the produced ammonia would be found, discarding the pellet containing the plaque.

\section{Statistical analysis}

The data were analyzed using the Statistical Package for Social Sciences (SPSS Inc. Released 2009. PASW Statistics for Windows, Version 18.0. Chicago: SPSS Inc., IL, USA).

Descriptive analysis of the variables was carried out to characterize the sample. Results of cariesfree and caries-active subjects were compared. Shapiro Wilk and Levene test were carried out to determine normality of data distribution and variance homogeneity. Mann-Whitney test was used to compare both groups. A significance level of 0.05 was adopted for all tests.

\section{RESULTS}

Ammonia concentration (mM, standard deviation, median, interquartile range) for saliva and plaque produced by urease activity ADS system for cariesfree and caries-active groups are shown in Table 1. Ammonia released by the urease activity on saliva and plaque samples was significantly higher $(p<0.01)$ for caries-free subjects than for cariesactive subjects. Similar results were obtained for ammonia released by the ADS system.

Urease activity was measured by quantification of ammonia produced from $25 \mu$ moles urea (Fisher Scientific, Pittsburgh, PA, USA). ADS and urease activities were normalized to protein content and defined as $\mu \mathrm{mol}$ ammonia liberated [minute $\mathrm{x}(\mathrm{mg}$ of protein) $]^{-1}$.

The results indicate that the urease activity in saliva (3.024 vs $0.437, p=0.010)$ and plaque (18.120 vs $0.370, p=0.033$ ) were significantly higher for caries-free subjects. Similarly, the ADS activity in saliva (6.050 vs $1.350, p=0.020)$ and plaque ( 8.830 vs $1.210, p=0.026)$ were significantly higher for caries-free subjects (see Table 2).

Shapiro-Wilk and Levene test showed that data was not normally distributed and variances were not homogeneous. The statistical power for ammonia concentration comparisons was 0.9 and for urease and ADS system activity comparisons, as the effect size was smaller, decreased to 0.6. 
Table 1-Ammonia concentration ( $\mathrm{mM}$ ), standard deviation, median, interquartile range, and p-value for saliva and plaque produced by urease and arginine deiminase system (ADS) for caries-free and caries-active subjects

\begin{tabular}{|c|c|c|c|c|c|}
\hline Urealisis & Saliva & Media & 0.089 & 0.04 & $0.003^{*}$ \\
\hline & & SD & 0.0429 & 0.0199 & \\
\hline & & Median & 0.082 & 0.032 & \\
\hline & & IR & 0.033 & 0.028 & \\
\hline & Plaque & Media & 0.113 & 0.032 & $0.001^{*}$ \\
\hline & & SD & 0.059 & 0.013 & \\
\hline & & Median & 0.098 & 0.028 & \\
\hline & & IR & 0.049 & 0.014 & \\
\hline \multirow[t]{8}{*}{ ADS } & Saliva & Media & 0.087 & 0.058 & $0.001^{*}$ \\
\hline & & SD & 0.0179 & 0.014 & \\
\hline & & Median & 0.087 & 0.055 & \\
\hline & & IR & 0.011 & 0.015 & \\
\hline & Plaque & Media & 0.071 & 0.05 & $0.008^{*}$ \\
\hline & & SD & 0.0198 & 0.0128 & \\
\hline & & Median & 0.071 & 0.048 & \\
\hline & & IR & 0.019 & 0.067 & \\
\hline
\end{tabular}

$\mathrm{SD}=$ Standard deviation; IR=Interquartile range; *Mann-Whitney test

Table 2- Urease and arginine deiminase system (ADS) activity ( $\mu \mathrm{mol}$ min-1mg prot.-1) in saliva and plaque for caries-free and caries-active subjects

\begin{tabular}{|c|c|c|c|c|c|}
\hline & & & Caries-Free & Caries-Active & p-value \\
\hline \multirow[t]{8}{*}{ Urealisis } & Saliva & Media & 3.024 & 0.437 & $0.010^{*}$ \\
\hline & & SD & 2.791 & 0.196 & \\
\hline & & Median & 1.66 & 0.47 & \\
\hline & & IR & 4.12 & 0.26 & \\
\hline & Plaque & Media & 18.12 & 0.37 & $0.033^{*}$ \\
\hline & & SD & 26.929 & 0.156 & \\
\hline & & Median & 2.9 & 0.4 & \\
\hline & & IR & 17.58 & 0.3 & \\
\hline \multirow[t]{8}{*}{ ADS } & Saliva & Media & 6.05 & 1.35 & $0.020^{*}$ \\
\hline & & SD & 5.808 & 0.548 & \\
\hline & & Median & 3.65 & 1.25 & \\
\hline & & IR & 3.05 & 0.73 & \\
\hline & Plaque & Media & 8.83 & 1.21 & $0.026^{*}$ \\
\hline & & SD & 10.666 & 0.392 & \\
\hline & & Median & 3.5 & 1.15 & \\
\hline & & IR & 8.7 & 0.52 & \\
\hline
\end{tabular}

$\mathrm{SD}=$ Standard deviation; IR=Interquartile range; *Mann-Whitney test

\section{DISCUSSION}

In spite of preventive Dentistry development in recent years, dental caries remains the most prevalent oral disease, generating an epidemiological problem in all countries ${ }^{27}$. As a result, dental research is constantly exploring new strategies in the prevention and treatment of this disease ${ }^{24}$.

Oral bacteria that colonize dental structures to form a dental biofilm coexist in a dynamic equilibrium that is compatible with dental integrity 3,5,21,22. Composition and metabolic changes in oral biofilm may generate an acidification that favors the growth 
of an acidogenic and aciduric microbiota, with the presence of Streptococcus mutans and Lactobacillus spp., that are associated with an increase in caries susceptibility ${ }^{3,20}$. On the other hand, less aciduric microorganisms as Streptococcus sanguinis and Streptococcus gordonii may contribute to plaque alkalinization, generating ammonia which favors the equilibrium between mineralization and demineralization, playing a key role in plaque $\mathrm{pH}$ homeostasis, preventing the emergence of a cariogenic microbiota, which could be a major impediment to the development of dental caries ${ }^{24,31}$. These microorganisms are associated with dental health ${ }^{1,2,10}$.

Caries-free subjects are shown to have a high ammonia generation activity by urease and arginine deiminase system ${ }^{15,24}$. Similarly, in our study, results in caries-free subjects showed more ammonia generation than in caries-active subjects, for both saliva and plaque samples.

In saliva, results in urease activity were 6.9 times, and in arginine deiminase system activity they were 4.5 times higher in caries-free subjects when compared to caries-active subjects. Nascimento, et al. ${ }^{24}$ (2009) and Gordan V, et al. ${ }^{15}$ (2010) showed similar results, with caries-free subjects having a higher urease activity in saliva and plaque samples compared to caries-active groups.

In plaque, results in urease activity were 48 times higher, and in arginine deiminase system they were 7 times higher for caries-free subjects. A similar result was obtained by Nascimento, et al. ${ }^{24}$ (2009) and Gordan, et al. ${ }^{15}$ (2010).

In our study, in caries-free subjects, urease and arginine deiminase system activities in saliva showed similar performance, while, in plaque, urease system showed a higher ammonia generation compared to arginine deiminase system, being plaque the one that generates most activity in these patients. This finding is similar to what was found by Sissons, et al. ${ }^{29}$ (1988), where urease activity in dental plaque of caries-free subjects was higher than in saliva from the same patients.

The association between caries-free subjects and a higher ammonia generation as obteined in our study, in both microbial plaque and saliva from arginine and/or urea may inhibit the development of a pathogenic microbiota, in an acidic oral environment ${ }^{6}$. A key virulence attribute of $S$. mutans is the fact that it can grow and continue to be active in low $\mathrm{pH}$ environments, but it can be relatively weak when placed in the same environment with microorganisms associated with healthy microbiota, as shown by in vitro results ${ }^{7}$. Alternatively, studies have shown that low $\mathrm{pH}$ levels may inactivate urease activity ${ }^{25,29}$.

Patients with low levels of urease have low capacity to neutralize glycolitic acidification even though high levels of urea are available ${ }^{30}$. In our study, it was shown that even in patients with the same quantity of available substrate (urea $=25$ umoles), different ammonia production was observed, as explained by the different enzymatic activity of diverse individuals. It is possible that low urease activity may also be associated with low levels of urease owning bacterias ${ }^{14}$. Alkali generation is important in the physiology, ecology and pathogenicity of dental biofilms. A substantial body of evidence from microbiological, genetic, and biochemical analyses and clinical studies has suggested that the alkalinogenic potential of dental biofilms may be used as a strategy for caries control ${ }^{19}$.

The most important point to consider is to validate a methodology in a population with which a similar study has never been conducted. The majority of studies in this line are made with the U.S. population. There is no precedent in Latin America, so it is interesting to make this study with a different population. It shows that the alkaline production can play a significant role in the genesis and prevention of dental caries.

How about mentioning that previous work has shown that "Although higher urease activity in saliva of caries-experienced and caries-free subjects was evident, no significant difference was found between the groups ${ }^{15}$. Our study does show a significant difference and that is why this manuscript and study are relevant.

\section{CONCLUSIONS}

The current results support that alkali generation is related with caries activity and DMFT values. Caries-free subjects had a higher ammonia generation activity by urease and arginine deiminase system for both saliva and plaque samples than low caries-active subjects. According to the results, the presented hypothesis is accepted: increased production of alkaline substances by dental biofilm bacterial strains and saliva is associated with low incidence of dental caries lesions. Ammonia generation from arginine and/or urea may have a great impact in oral environment; they could be used as a risk predictor of decay.

\section{Clinical relevance}

The most significant finding of this study is that the capacity of plaque bacteria to metabolize arginine and/or urea varies greatly among patients and tooth sites of different caries status, which may profoundly affect the resistance or susceptibility of the hosts to dental caries. 


\section{ACKNOWLEDGEMENTS}

This study was supported by FONIS, Chile, Grant \# SA13I20205.

\section{REFERENCES}

1- Aas JA, Griffen AL, Dardis SR, Lee AM, Olsen I, Dewhirst FE, et al. Bacteria of dental caries in primary and permanent teeth in children and young adults. J Clin Microbiol. 2008;46(4):1407-17. 2- Becker MR, Paster BJ, Leys EJ, Moeschberger ML, Kenyon SG, Galvin JL, et al. Molecular analysis of bacterial species associated with childhood caries. J Clin Microbiol. 2002;40(3):1001-9.

3- Bradshaw DJ, Marsh PD. Analysis of $\mathrm{pH}$-driven disruption of oral microbial communities in vitro. Caries Res. 1998;32(6):456-62. 4- Bradshaw DJ, McKee AS, Marsh PD. Effects of carbohydrate pulses and $\mathrm{pH}$ on population shifts within oral microbial communities in vitro. J Dent Res. 1989;68(9):1298-302.

5- Burne RA. Oral streptococci... products of their environment. J Dent Res. 1998;77(3):445-52.

6- Burne RA, Marquis RE. Alkali production by oral bacteria and protection against dental caries. FEMS Microbiol Lett. 2000;193:16.

7- Chen YY, Weaver CA, Burne RA. Dual functions of Streptococcus salivarius urease. J Bacteriol. 2000;182(16):4667-9.

8- Clancy A, Burne RA. Construction and characterization of a recombinant ureolytic Streptococcus mutans and its use to demonstrate the relationship of urease activity to $\mathrm{pH}$ modulating capacity. FEMS Microbiol Lett. 1997;151:205-11.

9- Clancy KA, Pearson S, Bowen WH, Burne RA. Characterization of recombinant, ureolytic Streptococcus mutans demonstrates an inverse relationship between dental plaque ureolytic capacity and cariogenicity. Infect Immun. 2000;68(5):2621-9.

10- Corby PM, Lyons-Weiler J, Bretz WA, Hart TC, Aas JA, Boumenna $T$, et al. Microbial risk indicators of early childhood caries. J Clin Microbiol. 2005;43(11):5753-9.

11- Dumitrescu AL, Kawamura M. Etiology of periodontal disease: dental plaque and calculus. In: Dumitrescu AL (ed.). Etiology and pathogenesis of periodontal disease. Berlin: Springer-Verlag 2010. pp 1-38.

12- Epstein SR, Mandel I, Scopp IW. Salivary composition and calculus formation in patients undergoing hemodialysis. J Periodontol. 1980;51(6):336-8.

13- Ertuğrul F, Elbek-Cubukçu C, Sabah E, Mir S. The oral health status of children undergoing hemodialysis treatment. Turk J Pediatr. 2003;45(2):108-13.

14- Featherstone JD. The science and practice of caries prevention. J Am Dent Assoc. 2000;131(7):887-99.

15- Gordan VV, Garvan CV, Ottenga ME, Schulte R, Harris P, McEdward D, et al. Could alkali production be considered an approach for caries control? Caries Res. 2010;44:547-54.
16- Imfeld T, Birkhed D, Lingström P. Effect of urea in sugar-free chewing gums on $\mathrm{pH}$ recovery in human dental plaque evaluated with three different methods. Caries Res. 1995;29(3):172-80. 17- Kleinberg I. Effect of urea concentrations on plaque $\mathrm{pH}$ in vivo. J Dent Res. 1961;40:751-2.

18- Kopstein J, Wong OM. The origin and fate of salivary urea and ammonia in man. Clin Sci Mol Med. 1977;52(1):9-17.

19- Liu YL, Nascimento M, Burne RA. Progress toward understanding the contribution of alkali generation in dental biofilms to inhibition of dental caries. Int J Oral Sci. 2012;4(3):135-40.

20- Loesche WJ. Role of Streptococcus mutans in human dental decay. Microbiol Rev. 1986;50(4):353-80.

21- Margolis HC, Duckworth JH, Moreno EC. Composition and buffer capacity of pooled starved plaque fluid from caries-free and caries-susceptible individuals. J Dent Res. 1988;67(12):1476-82. 22- Marsh PD. Microbial ecology of dental plaque and its significance in health and disease. Adv Dent Res. 1994;8(2):263-71.

23- Morou-Bermudez E, Elías-Boneta A, Billings RJ, Burne RA, Garcia-Rivas V, Brignoni-Nazario, et al. Urease activity in dental plaque and saliva of children during a three-year study period and its relationship with other caries risk factors. Arch Oral Biol. 2011;56(11):1282-9.

24- Nascimento MM, Gordan VV, Garvan CW, Browngardt CM, Burne RA. Correlations of oral bacterial arginine and urea catabolism with caries experience. Oral Microbiol Immunol. 2009;24(2):89-95.

25- Nascimento MM, Liu Y, Kalra R, Perry S, Adewumi A, Xu X, Primosch $R E$, et al. Oral arginine metabolism may decrease the risk for dental caries in children. J Dent Res. 2013;92(7):604-8. 26- Nauntofte B, Tenovuo J, Lagerlöf F. Secretion and composition of saliva. In: Fejerskov O, Kidd EA (eds.). Dental caries: the disease and its clinical management. Oxford: Wiley-Blackwell; 2003. pp 7-27.

27- Petersen PE, Bourgeois D, Ogawa H, Estupinan-Day, S, Ndiaye C. The global burden of oral diseases and risks to oral health. Bull World Health Organ. 2005;83:661-9.

28- Peterson S, Woodhead J, Crall J. Caries resistance in children with chronic renal failure: plaque $\mathrm{pH}$, salivary $\mathrm{pH}$, and salivary composition. Pediatr Res. 1985;19(8):796-9.

29- Sissons $\mathrm{CH}$, Cutress TW. $\mathrm{pH}$ changes during simultaneous metabolism of urea and carbohydrate by human salivary bacteria in vitro. Arch Oral Biol. 1988;33:579-87.

30- Sissons $\mathrm{CH}$, Cutress TW, Pearce EI. Kinetics and product stoichiometry of ureolysis by human salivary bacteria and artificial mouth plaques. Arch Oral Biol. 1985;30(11-12):781-90.

31- Van Wuyckhuyse BC, Perinpanayagam HE, Bevacqua D, Raubertas RF, Billings RJ, Bowen $\mathrm{WH}$, et al. Association of free arginine and lysine concentrations in human parotid saliva with caries experience. J Dent Res. 1995;74(2):686-90.

Zabokova Bibilova E, Sotirovska Ivkovska A, Ambarkova V. Correlation between salivary urea level and dental caries. Prilozi. 2012;33(1):289-302. 